\title{
Acute Supurative Thyroiditis in Post Cimino Infection Patient
}

\author{
Ferdy Royland Marpaung ${ }^{1}$, Sidarti Soehita ${ }^{1}$ \\ ${ }^{I}$ Department of Clinical Pathology, Faculty of MedicineUniversitas Airlanggal, Dr Soetomo Academic Hospital \\ Surabaya Indonesia
}

\begin{abstract}
Acute suppurative thyroiditis (AST) is a rare clinical case that must be treated immediately because of its fatality, especially cases of swelling on thyroid area accompanied by fever. AST is often preceded by infection, therefore it is necessary to find the source.A 40 years old woman came to the hospital with complain of pain on the swollen neck,difficultyonswallowandfever. The patient suffered from chronic kidney disease (CKD). One week before she had an AV hemodialysis shunt infection. Laboratory results showed an increase of fT4 $3.5 \mathrm{ug} / \mathrm{dL}$ and a decrease in TSH $(0.015 \mathrm{uIU} / \mathrm{mL})$, leukocytosis and an increase of CRP. Thyroid ultrasound showed an abscess in entire left thyroid while thyroid lobe FNAB showed AST. Pus culture showed the growth of Staphylococcus aureus bacteria. Thyroid test supported an AST with hyperthyroidism and should be treated immediately. Three weeks after treatment the patient was euthyroid and had drainage of the pus. AST occurred due to hemodialysis AV shunt infection. Laboratory results show the presence of leukocytosis and increased of CRP levels, supporting signs of inflammation. Pus culture revealed significant growth of Staphylococcus aureus and improved with Clyndamycin therapy. To our knowledge, this is the first AST case preceded by hemodialysis AV shunt infection.Cases of swelling on thyroid, painful swallowing, fever, preceded by a shunt AV hemodialysis infection were considered to examine thyroid markers, ultrasound and FNAB for early diagnosis of AST because it can be life-threatening.
\end{abstract}

Keyword: Acute suppurative thyroiditis, Hyperthyroid, Chronic Kidney Disease, Arteriovenous Shunt, Hemodialysis

\section{Introduction}

Thyroiditis is an inflammation of the thyroid that can be caused by various conditions. Conditions that can cause this include autoimmune disorders, viral, bacterial, fungal and other infections ${ }^{1}$. Acute suppurative thyroiditis (AST) is a very rare type of thyroiditis. Thyroid abscess and AST account for only $0.1 \%-0.7 \%$ of all thyroid disorders. AST is common in patients with Hashimoto's thyroiditis and thyroid cancer. AST is associated with the persistence of

\section{Corresponding author:}

Ferdy Royland Marpaung

E-mail: ferdyoke@gmail.com ducts originating from the 3 rd or 4 th bronchial sac which can lead to recurrent thyroid abscess. Most cases of infection spread to the thyroid gland via a piriform sinus shunt. The left lobe of the thyroid gland is more commonly affected. AST can be lifethreatening if not treated promptly, and result in $12 \%$ or more in mortality due to thyroid storm and sepsis ${ }^{2}$. The diagnosis of AST is often delayed due to atypical clinical features. AST is rare because the anatomical and physiological characteristics of the gland have unique infection resistance, namely the bactericidal nature of colloidal materials, increased vascularity, and the presence of iodine in the thyroid gland. A thyroid abscess presents as a very painful swelling. The differential diagnosis for thyroid gland pain is 
8 Medico-legal Update, January-March 2022, Vol.22, No. 1

very limited, the most common being subacute and chronic thyroiditis ${ }^{3}$.

\section{Case Report}

A 40-year-old woman was admitted to the hospital with the chief complaint of swollen neck pain for 2 days accompanied by difficulty swallowing and fever. The patient has never had the same complaint before. One week before, the patient had surgery due to infection in the AV hemodialysis shunt.The patient had history of chronic kidney failure (CKD) stage $\mathrm{V}$ about 1 month ago and routinely underwent hemodialysis $(2 \mathrm{x} /$ week). The patient suffered from hypertension about 7 years ago. There was no history of Diabetes Mellitus and thyroid disorders.

\section{Physical examination (upon arrival at ER)}

The patient was generally weak, conscious (GCS 4-5-6), blood pressure $110 / 70 \mathrm{mmHg}$, pulse of 92 $\mathrm{x} /$ minute, respiration rate of $20 \mathrm{x} /$ minute, axilla temperature of $38{ }^{\circ} \mathrm{C}$. Other physical examination revealed left anterior swelling of neck (warm +, supple + , tenderness + , size 4-5 cm, up and down when swallowing and painful) (Figure 1)

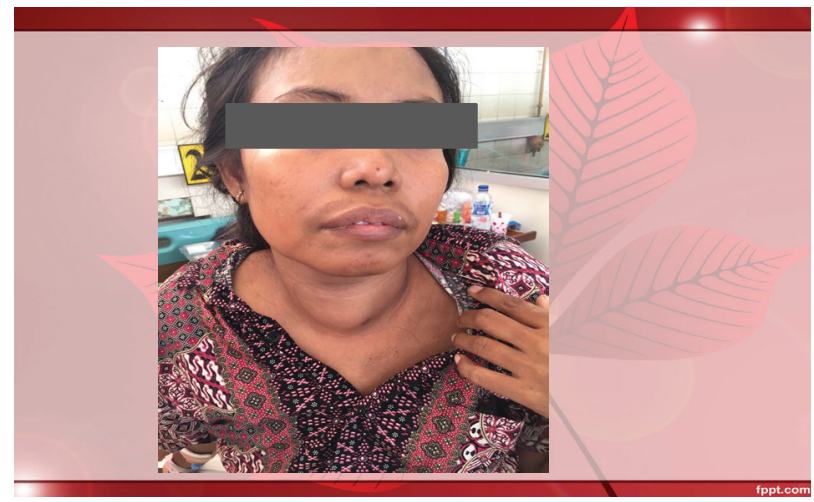

Figure 1. The left neck is swollen and painful Supporting examination

Table 1. Hematological examination

\begin{tabular}{|c|c|c|c|c|}
\hline Hematology & $25 / 9$ & $1 / 10$ & $3 / 10$ & $12 / 10$ \\
\hline $\mathrm{WBC}(\mathrm{x} 103 / \mu \mathrm{L})$ & 17.15 & 22.98 & 8.62 & 7.07 \\
\hline Neu (\%) & 87.1 & 86.3 & 77.8 & 72.0 \\
\hline $\operatorname{Lym}(\%)$ & 8.4 & 6.53 & 17.41 & 11.9 \\
\hline Mono (\%) & 3.6 & 5.34 & 6.55 & 8.2 \\
\hline Eos $(\%)$ & 0.2 & 0.01 & 0.59 & 0.5 \\
\hline Baso(\%) & 0.5 & 0.44 & 0.6 & 0.2 \\
\hline $\mathrm{RBC} \times 106 / \mu \mathrm{L}$ & 4.08 & 4.030 & 4.126 & 3.95 \\
\hline $\mathrm{Hb}(\mathrm{g} / \mathrm{dL})$ & 8.7 & 8.3 & 6.7 & 7.7 \\
\hline Hct $\%$ & 36.8 & 36.64 & 35.28 & 33.2 \\
\hline MCV (fL) & 90.2 & 85.94 & 85.51 & 84.1 \\
\hline $\mathrm{MCH}(\mathrm{pg})$ & 30.2 & 30.43 & 30.93 & 29.9 \\
\hline $\mathrm{MCHC}(\mathrm{g} / \mathrm{dL})$ & 33.5 & 35.41 & 36.17 & 35.5 \\
\hline RDW (\%) & 14.1 & 13.03 & 12.75 & 13.2 \\
\hline Platelet $(\mathrm{x} 103 / \mu \mathrm{L})$ & 100 & 121 & 114 & 128 \\
\hline
\end{tabular}


Medico-legal Update, January-March 2022, Vol.22, No. 19

Table 2. Clinical chemistry examination

\begin{tabular}{|c|c|c|c|c|c|c|}
\hline Parameter & $\mathbf{2 5 / 9}$ & $\mathbf{1 / 1 0}$ & $\mathbf{4 / 1 0}$ & $\mathbf{7 / 1 0}$ & $\mathbf{1 4 / 1 0}$ & Ref Range \\
\hline $\mathrm{Na}(\mathrm{mmol} / \mathrm{L})$ & 133 & 139 & 140 & 135 & 134 & $136-144$ \\
\hline $\mathrm{K}(\mathrm{mmol} / \mathrm{L})$ & 5.1 & 4.1 & 3.5 & 4.9 & 3.6 & $3.8-5.0$ \\
\hline $\mathrm{Cl}(\mathrm{mmol} / \mathrm{L})$ & 100 & 99 & 105 & 104 & 103 & $97-103$ \\
\hline $\mathrm{Ca}(\mathrm{mg} / \mathrm{dL})$ & 7.2 & 8 & 8.6 & - & 8.4 & $8.5-10.1$ \\
\hline $\mathrm{Pho}(\mathrm{mg} / \mathrm{dL})$ & 6 & 6.1 & 5.6 & - & - & $2.5-4.9$ \\
\hline $\mathrm{Alb}(\mathrm{g} / \mathrm{dL})$ & 3.2 & 3.1 & 3.2 & 3.4 & 3.1 & $3.4-5.0$ \\
\hline $\mathrm{UA}(\mathrm{mg} / \mathrm{dL})$ & 10.4 & 4.9 & - & - & - & $2.6-7.2$ \\
\hline $\mathrm{CRP}(\mathrm{mg} / \mathrm{dL})$ & & 12 & & & & $<5$ \\
\hline
\end{tabular}

Table 3. Thyroid plasma examination

\begin{tabular}{|c|c|c|c|c|c|c|}
\hline Parameter & $\mathbf{1 / 1 0}$ & $\mathbf{9 / 1 0}$ & $\mathbf{1 2 / 1 0}$ & $\mathbf{1 4 / 1 0}$ & $\mathbf{1 9 / 1 0}$ & Ref Range \\
\hline $\mathrm{fT} 4(\mathrm{ug} / \mathrm{dL})$ & 3.5 & 3.73 & 1.8 & 1.68 & 1.21 & $0.89-1.76$ \\
\hline $\mathrm{TSH}(\mathrm{uIU} / \mathrm{hL})$ & 0.015 & 0.015 & 0.02 & 0.018 & 0.02 & $0.55-4.78$ \\
\hline Anti TPO (IU/mL) & Neg (27) & & & & & $\begin{array}{c}<50: \text { neg } \\
>75: \mathrm{BL}\end{array}$ \\
\hline Anti TRAb (IU/L) & $\mathrm{Neg}$ & & & & & $0.00-1.73$ \\
\hline
\end{tabular}

Table 4. Immunology examination

\begin{tabular}{|c|c|c|c|}
\hline Parameter & $\mathbf{4 / 1 0}$ & $\mathbf{9 / 1 0}$ & Ref Range \\
\hline HBsAg & Non Reactive & - & - \\
\hline HIV & Non Reactive & - & - \\
\hline ANA tets & - & 24.56 & - \\
\hline $\mathrm{C} 3(\mathrm{mg} / \mathrm{L})$ & - & 85 & - \\
\hline $\mathrm{C} 4(\mathrm{mg} / \mathrm{dL})$ & - & 49 & \\
\hline
\end{tabular}


ThyroidUltrasoundResults $(8 / 10)$

Thereisanabscess in the entire left lobe of the thyroid with a sizeof $3.54 \times 2.2 \times 5.49 \mathrm{~cm}$

Thyroid FNAB Results (1/10)

The smearcontains a distributionoflymphocytes and PMN cells as well as macrophagecystsagainst a broaderythrocytebackground. Conclusion: Acutesuppurativethyroiditis (Figure 2).

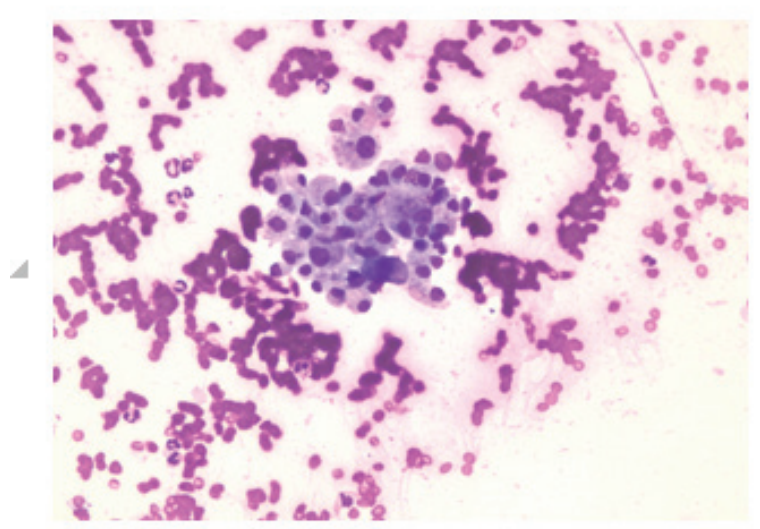

Figure 2. FNAB results show an AST

\section{Pus culture examination (14/10):}

There was a growth of Staphylococcus aureus with antimicrobial sensitivity results showed Sensitive to Gentamycin, Ampicillin-Sulbactam, Oxacillin, Cotrimoxazole, Erythromycin, Clindamycin, Quinopistrine-Dalfopristine, Levofloxacin, Movifloxacin, but Resistance to Ampicillin and Tetracycline.

Head and Neck Surgery Division Consultation

Head and neck surgery division plan todo drainage-incisions thyroid abscess after patient had euthyroid state condition. The diagnosis wasAcute Suppurative Thyroiditis (pro-drainage-incision) + Hyperthyroid + Chronic Kidney Diseases stage V with regularhemodialysis.

Therapy:
1. High in calories and low in protein $2100 \mathrm{kcal}$

2. Amlodipine $1 \times 10 \mathrm{mg}$ oral

3. Paracetamol 3x500mg oral

4. Injection of Ceftriaxon $2 \times 1 g$ Intravenous change to Clindamycin $2 \times 300 \mathrm{mg}$ po (starting day 14)

5. Thyrozol 1x10mg oral, increase $3 \times 10 \mathrm{mg}$ (day 14)
6. Propranolol 3x10mg oral (14th day)
7. Folic acid $3 \times 1 \mathrm{mg}$ oral
8. Hemodialysis as scheduled $2 \mathrm{x}$ a week

\section{Discussion}

Abscess formation frequently occurs in children due to anatomic abnormalities of the hypopharyngeal region in result of piriform sinus fistulas. The occurrence of thyroid abscess in adults is extremely rare and may be caused by various causes such as foreign body trauma (FNAB, fishbone) and anatomical pressure. Hematogenous spread from distant sites is known to be the most common cause of thyroid infection, although the exact mechanism is unknown. The manifestation of thyroiditis is mostly local pain in the involved lobe, accompanied by pain and difficulty of swallowing. Symptoms of fever and chills may occur depending on the virulence of the microorganism and the occurrence of sepsis. ${ }^{1-2,4-8}$

Primary thyroid abscess from AST is a rare type of head and neck infection because the thyroid gland is known to have infection-fighting mechanisms. Thyroid protection includes rich blood supply and lymphatic drainage, high iodine content of the gland which is bactericidal, certain range of the gland from other neck structures by the facial plane, and formation of hydrogen peroxide within the gland for thyroid hormone synthesis.AST by bacterial infection is usually more painful than patients with subacute 
thyroiditis. Subacute thyroiditis usually displays as severe localized tenderness, but is less likely to be thyrotoxicosis ( $60 \%$ of patients). ${ }^{1}$

This patient had left neck lump painfollowing fever and strain in swallowing. It was suspected that there was a hematogenous spread of bacteria creating thyroid infection because the patient had just had an AV hemodialysis shunt transfer operation 1 week earlier. Prior to the surgery, the patient experienced fever, chills, and the left AV hemodialysis shunt was starting to be red, enlarged and painful bump.

The patient has leukocytosis and elevated CRP that supports signs of inflammation. High FT4 levels and low TSH levels indicate a hyperthyroid condition. Hyperthyroidism in thyroiditis may occur naturally over weeks to months. The processcontinues until a condition of disequilibrium occurs(a condition of hypothyroidism with low TSH). These patients should be treated immediately because AST is a lifethreatening condition ( $12 \%$ of mortality if not treated immediately). Mortalitymay occur in result of thyroid storm and sepsis. Thyroid storm generates when hyperthyroidism is not treated, resulting in symptoms of fever, increased pulse, blood pressure, nausea, vomiting and agitation.

Ultrasound examination revealed abscess in the thyroid gland or evidence of enlargement lobe, while FNABdetermine the presence of infection as it is possibly done simultaneously with culture. ${ }^{1}$ The results of the patient's ultrasound concluded that there was an abscess in almost the entire left lobe of the thyroid with a size of $3.54 \times 2,2 \times 5.49 \mathrm{~cm}$. FNAB results showed that the smear contained the distribution of lymphocytes and PMN cells and cyst macrophages with an erythrocyte background, no signs of malignancy were found.

This patient was planned for drainage-incision of the thyroid abscess after euthyroid status. Base incision and drainage is a necessary surgical procedure as therapy, but care must be taken to treat hyperthyroidism first to avoid postoperative thyroid storm situation and other unwanted metabolic effects.

Appropriate antibiotics should be given accordingly to the causative organism.Pus culture results of this patient exhibited significant growth of Staphylococcus aureus. The patient came to the hospital and received an injection of Ceftriaxone $2 \times 1$ gramintravenous as empiric treatment. Furthermore, after the results of the pus culture antibiogram released, the patient's antibiotic was changed to Clindamycin $2 \times 300 \mathrm{mg}$ oral (starting on the 14th day).

The patient also suffers from chronic kidney failure (CKD) which is able to cause immune system disorders. Disorders can be in the form of systemic inflammation and immunosuppression. ${ }^{10}$ There is an increase in proinflammatory cytokines in CKD such as pentraxine, in addition to dysfunction of phagocytes, $\mathrm{B}$ and $\mathrm{T}$ cells. ${ }^{11-13}$ Hemodialysis therapy is the key to improving the general condition and the patient's immune system.

The patient had incision and drainage done after normal thyroid levels. The prognosis is excellent with general maintenance of thyroid function, however, post-thyroiditis thyroid function tests should be monitored to ensure that a thyroid disorder is not present.

To our knowledge, this is the first case report of suspected hemodialysis AV shunt infection causing hematogenous spread to the thyroid organ leading to AST.

\section{Conclusion}

The patient was diagnosed with AST which was probably caused by post-infectious AV shunt hemodialysis. Cases of neck swelling and fever 
12 Medico-legal Update, January-March 2022, Vol.22, No. 1

after infection with AV hemodialysis shunt are recommended for a thorough thyroidtesting, ultrasound and FNAB for early diagnosis of AST because its life-threatening threat.

Conflict of Interest: The author declare that they have no conflict of interest.

Source of Funding: None.

Acknowledgements: We would like to thank the patient who have voluntarily participated

Ethical Approval: This study approved by the Ethics Committee of Dr Soetomo Academic Hospital

\section{References}

1. Brent G, Larsen P, Davis T. Williams Textbook of Endocrinology. 13th ed. Melmed S, Polonsky KS, Larsen PR, Kronenberg HM, editors. Elsevier. Canada: Elsevier; 2016. 442-445 p.

2. Paes JE, Burman KD, Cohen J, Franklyn J, McHenry CR, Shoham S, et al. Acute Bacterial Suppurative Thyroiditis: A Clinical Review and Expert Opinion. Thyroid. 2010 Mar;20(3):24755.

3. Lamani YP, Basarkod SI, Telkar SR, Goudar B V., Ambi U. Thyroid abscess in Immuno Compromised patient: A case report. J Clin Diagnostic Res. 2012;6(1):106-7.

4. Hazard JB. Thyroiditis: A Review Part I. Am J Clin Pathol. 1955 Mar 1;25(3):289-98.

5. Coret A, Heyman Z, Bendet E, Amitai M, Itzchak I, Kronberg J. Thyroid abscess resulting from transesophageal migration of a fish bone:
Ultrasound appearance. J Clin Ultrasound. 1993 Feb;21(2):152-4.

6. Pearce EN, Farwell AP, Braverman LE. Thyroiditis. N Engl J Med. 2003 Jun 26;348(26):2646-55.

7. Oluwayemi IO, Abduraheem FO, Agaja OT, Oke OJ, Ogundare EO, Ajite AB, et al. Acute suppurative thyroiditis: A case report. Curr Pediatr Res. 2016;20(1-2):88-91.

8. Akuzawa N, Yokota T, Suzuki T, Kurabayashi M. Acute suppurative thyroiditis caused by Streptococcus agalactiae infection: a case report. Clin Case Reports. 2017 Aug;5(8):1238-42.

9. Sharma B, Bhavi V, Nehra H, Kumar A, Saran S, Mathur S. Thyroid abscess: A rare case report and review of literature. Thyroid Res Pract. 2018;15(1):49.

10. Kurts C, Panzer U, Anders H-J, Rees AJ. The immune system and kidney disease: basic concepts and clinical implications. Nat Rev Immunol. 2013 Sep 16;13:738. Available from: $10.1038 /$ nri3523

11. Carrero JJ, Stenvinkel P. Inflammation in EndStage Renal Disease-What Have We Learned in 10 Years? Semin Dial. 2010;23(5):498-509.

12. Lech M, Rommele C, Anders H-J. Pentraxins in nephrology: C-reactive protein, serum amyloid $\mathrm{P}$ and pentraxin-3. Nephrol Dial Transplant. 2013 Apr 1;28(4):803-11.

13. Cohen G, Hörl W. Immune Dysfunction in Uremia-An Update. Toxins (Basel). 2012 Oct 24;4(11):962-90. 